\title{
LGBT at USNA
}

\author{
Clementine Fujimura*, Clara Navarro
}

United States Naval Academy, USA

Copyright $\bigcirc 2016$ by authors, all rights reserved. Authors agree that this article remains permanently open access under the terms of the Crative Commons Attribution License 4.0 international License.

\begin{abstract}
This research addresses significant cultural changes in terms of gender relations that are occurring in the United States military today and in particular at the academy level. This article focuses on the LGBT community at the United States Naval Academy and posits that, in order to fully understand and support the success of LGBT midshipmen at the United States Naval Academy, it is important to understand the diversity of the LGBT community in general from a grassroots perspective. Depending on self-identification and the process in self-identification of individual midshipmen, for example, experiences vary greatly. This paper seeks to analyze the experiences of those individuals identifying as LGBT at USNA based on an ethnographic study involving the collection of coming-out stories by and interviews with midshipmen as well as participant-observation research in the community. It is the researcher's initial conclusion that a support network for LGBT midshipmen is essential when it comes to their development as young adults, as officers and as potential leaders in the military.
\end{abstract}

Keywords LGBTQ, LGBT, Military Culture, Anthropology, United States Naval Academy Culture

\section{Introduction}

This article discusses the LGBT community in the United States military since the repeal of Don't Ask Don't Tell (DADT) and in particular, at the United States Naval Academy in Annapolis. The article posits that, in order to fully understand and support the success of LGBT midshipmen at the United States Naval Academy, it is important to understand the diversity and cultural tensions LGBT midshipmen experience through ethnographic research and looking beyond the walls of the academy to civilian institutions for guidance. The processes individual midshipmen undergo to self-identify as LGBT vary and the outcomes, how they identify, are fluid and dynamic. This study analyzes experiences of individuals identifying as LGBT at USNA that have been expressed and recorded during a two-year ethnographic study involving collection of coming-out stories by and interviews with midshipmen, analysis of social media, as well as participant-observation research in clubs and at non-academic functions. It is hoped that with this study the military and, in particular the Naval Academy, will find grounds to develop stronger and culturally appropriate support networks and resources for LGBT midshipmen and service members.

\section{Literature Overview}

The literature on gender in anthropology is vast, dating back to the 1960 's and 70 's. In the early 1970's, two pioneers helped establish the importance of gender in anthropological research, Sherry Ortner and Louise Lamphere (1974) [14], which led to the birth of Women's Studies as a program of study in higher education and the inclusion of gender in Anthropology as a significant category. It was not until the 1990's however that serious consideration was given to the inclusion of queer studies and the role of femininity and masculinity. This inclusion led to the change in programs from Women's Studies to Gender Studies and the publication of the Journal of Gender Studies in 1991.

From Ortner, this article takes a paradigm called "practice anthropology", which focuses on the relationship between individuals and social/economic structures that organize people's lives. Ortner seeks to reveal how people's reactions to experiences and daily behaviors ultimately perpetuate or change the dominant social order [10]. For this paper, the focus is on the interactions between a powerful institution guided by dominant ideas of masculinity and the less powerful whose stereotype clashes with what is ideal and powerful. Behaviors and activities of LGBT midshipmen ultimately are leading to change in the social order of the military.

Since the onset of gender studies, numerous scholars have contributed with a focus on same-sex cultures and cross-cultural gender diversity by such scholars as Jennifer Robertson and Serena Nanda [12]. Serena Nanda [13] for example, has contributed with ethnographic work in India 
but also Euro-America, among others regions of the world, in which she focuses on "transgenderism." When discussing gender differences in general, Nanda has pointed to the complexity of gender within transgendered communities. Her work theoretically informs and supports findings in this article by acknowledging the complexity of gender relations and identity formation, even in a seemingly uniform community like the military. LGBT, as an acronym does not do justice to the variation in gender identification. In her own words, Nanda seeks to bring our consciousness "about the cultural construction of sex, gender and sexualities and their relationship to each other in all cultures...(to enable us) to cross the barriers of cultural difference to a recognition of a greater shared humanity" [13] ( parenthesis inserted, italics in original). However even with this introduction to the complexity of diversification of gendered communities, Nanda denies transsexuals a place at the table, a group which is seen in discussions with LGBT midshipmen as an important group. To deny the group's personal identification as such is problematic from an ethnographic perspective.

Emergence of scholarly work in the past decade on LGBT in the military is promising. One pioneering product was the publication of Herek, Jobe and Carney's edited volume, Out in Force: Sexual Orientation and the Military in 1996. [8] The strength of this manuscript lies in its objective scholarly approach to the potential for including gays and lesbians in the military from mostly social and clinical psychological perspectives prior to the repeal of DADT. The potential for a positive outcome is addressed and compared to successful integration of LGBT professionals in foreign militaries.

Psychology has helped develop the field of LGBT studies in the military with significant work by such scholars as Burke (2011) [4], Cameron et al. (2011)[5], Fingerhut (2011) [6], Ramirez (2013) [16] and Johnson (2015) [9]. Of special interest for this article is the work by Johnson and his colleagues specifically because of their first-hand knowledge of the United States Naval Academy. Both Professors Johnson and Rosenstein (one of the co-authors) are professors at the institution: Dr. Johnson, a psychologist and Dr. Rubinstein, a sociologist with a specialization in gender studies. Dr. Johnson's article discusses the history of USNA as inhospitable to LGB professionals and the stigma that might still exist. From a psychological perspective, Johnson points out the stressors that may impede LGB people's work and ability to succeed both in formulating their personal identities and feelings concerning job satisfaction. Johnson emphasizes the important place for qualified psychologists to aid in the lives of LGB midshipmen and professionals.

Much of the literature points to the questions regarding the feasibility of gays in the military, an institution in which a culture of masculinity prevails. Barrett (1996) [1], for example, reviews the effects of hegemonic masculinity in the United States Navy through interviews with aviators, surface warfare officers and supply corps officers:
"Definitions of masculinity are relationally constructed through associations of difference: aviators tend to draw upon themes of autonomy and risk taking; surface warfare officers draw upon themes of perseverance and endurance; and supply officers draw upon themes of technical rationality. Further, these masculinities depend upon various contrasting definitions of femininity [1]. This article is helpful in that it provides insider's commentary, but lacks long-term observational studies and begs more insider narrative. Continuing the discussion of the feasibility and outcomes of the repeal of Don't Ask Don't Tell are the scholarly productions from the Palm Center. During deliberations this center produced articles and memo's that demonstrated that homosexuality has never been proven to impair military readiness [7].

This article hopes to contribute to scholarly and military understanding of LGBT midshipmen and officers at a point when many in the LGBT community still feel misunderstood, stigmatized and unsupported. The military is still coming to terms with openly accepting and providing for LGBT midshipmen, enlisted and officers. However, this moment of change offers LGBT members an advantage, as this is truly a time when the military needs to listen to LGBT needs, to learn from the community itself about the complexity and significance of its members to ensure the successful integration, ultimately, to help ensure mission success.

\section{Methodology}

This article relies mainly on ethnographic research conducted over a period of two years (2014-2016). Prior to conducting research, IRB approval was obtained to ensure that no-one would be harmed (HRPP Approval \# USNA.2013.0008-IR-EP7-A). From the onset, there was a concern that students would feel negative repercussions for participating in the research. For this reason, the research was put on hold for one year to ensure that USNA as a context for the study of the LGBT community could become more established after DADT. This timeframe was requested by the Superintendent of USNA at that time. Once the approval was received and the wait of one year completed, students from SPECTRUM, an LGBT club, were solicited. Many students from this community were eager to participate. Students interviewed are given letters as an alias. Quotes are taken from interviews that were conducted in person or in writing. Five subjects contributed by writing narrative statements about their coming-out experiences. Two transgender midshipmen offered interviews. Observations in the classroom came from faculty at USNA and revealed in interviews with the primary researcher. If observations were made by the researcher in class, it was openly discussed and students were made aware of the ongoing research. Students who offered their opinions signed consent forms that were 
approved by the IRB committee.

As mentioned above, the research is qualitative in nature, relying on oral and written narratives and ethnographic research. The most heavily utilized ethnographic method in this project is participant observation in which the researcher is immersed in the community, attending group functions and taking observational field notes. Of particular interest in the observations were how the midshipmen interacted with each other and how they reacted to and in LGBT discussions.

At this point in time, individual LGBT experiences cannot be quantified meaningfully due to the fact that LGBT culture at USNA is still in its infancy of coming out. Many students are concerned about attending LGBT events, much less going on record. Accessing midshipmen's narratives requires trust of the researcher. Personal contact and relationship building with those interviewed was paramount to open conversations. It can be surmised that the diversity within the LGBT community at USNA is as individualized as on civilian campuses however many of the gender identity groups remain unofficial, hidden and even stigmatized. Personal stories proved significant in demonstrating the diversity of experiences and choices of identifying as LGBT.

LGBT is used as the acronym unlike that found at many other civilian universities. This is mainly due to the fact that LGBT are the only letters under discussion as accepted or potentially accepted in the military. "Q"ueer, for example, is not, as of yet, incorporated into policy.

\section{Background to the LGBT Community at USNA}

On November 30, 1993, President Clinton signed into law the policy known as "Don’t Ask, Don't Tell," (DADT) after failing to overcome opposition to allow gay men and women to serve openly in the military. Although often referred to as a compromise, the Department of Defense (DoD) defined homosexuality as "an unacceptable risk to the high standards of morale, good order and discipline, and unit cohesion that are the essence of military capability." As a result, more than 13,000 members of the armed services were discharged under DADT and many of those who were not discharged felt they were unable to live freely, openly and honestly.

During DADT the Honor Concept became problematic for LGBT midshipmen. The Honor Concept reads:

Midshipmen are persons of integrity: We stand for that which is right.

We tell the truth and ensure that the full truth is known.

We do not lie.

We embrace fairness in all actions. (Bold added by author) We ensure that work submitted as our own is our own, and that assistance received from any source is authorized and properly documented. We do not cheat.
We respect the property of others and ensure that others are able to benefit from the use of their own property. We do not steal.

\section{- Honor Concept, USNA Brigade Honor Program}

As a result of DADT, LGBT midshipmen felt they could avoid lying if they about their sexuality or gender if they wanted to remain honorable. In fact, many chose to resign rather than feel dishonorable.

Beyond struggling internally with the Honor Concept and their feelings of integrity while serving silently under DADT, LGBT midshipmen were subjected to having to passively endure gay jokes and gay bashing. Moreover, midshipmen and officers who engaged in such use of language were commonly inadvertently rewarded by being acknowledged as less gay, that is, more warrior-like.

Despite the fear of retribution among LGBT midshipmen, a distinct LGBT community existed, albeit underground. Finding solace among each other, midshipmen gathered in particular clubs on the yard that was known by word of mouth to be the club for gay midshipmen to meet. These clubs officially served another function but evolved over time into the meeting places for LGBT midshipmen. One such club was the Italian Midshipman Club which, as one midshipman recounts was "the hot spot." (Midshipman N, April 2015)

On December 22, 2010, President Barack Obama signed a repeal of DADT into law. The formal repeal would not begin until 60 days after the President, Secretary of State and Chairman of the Joint Chiefs of Staff certified in writing that the military was sufficiently prepared for the change. The leadership began an investigation to address concerns in the military, some of which included:

- There would be a major disruption in cultural climate with the repeal of DADT

- That there would be more trouble with roommates

- That individuals would not feel comfortable in bathrooms

- That possible social disruption would detract from the mission

While a number of officers voiced their discontent at round-table discussions, midshipmen polled in roundtable discussions generally appeared less concerned. While some were nervous about bathroom and roommate situations, the vast majority of respondents in the investigation felt the concern was unfounded: "After all, open or not open, LGBT people are already here. Nothing will change" (Midshipman TS 2010). Indeed the repeal of DADT went smoothly and life at the Academy continued seamlessly.

\section{The Warrior Stereotype and Gender}

Still, the experience of being a midshipman at the Naval Academy is gendered. Naval Academy culture is based on the value of the "Manly Warrior" or the "hegemonic 
masculine" ideal, defined as: "a man who is independent, risk-taking, aggressive, heterosexual and rational" [1]. When this masculine warrior ideal is achieved, a midshipman is more likely to achieve acceptance, which leads to a sense of belonging among those who fit the ideal. It also leads to "othering" of those who do not.

Hegemonic masculinity is constructed and maintained in various ways. Some of these include:

- masculinizing of male bodies and minds in athletics $[3, p .4]$

- $\quad$ building unit cohesiveness through the maintenance of the "manly warrior" image such as body image and a workout ethic that are not simply for health.

- displaying endurance, toughness and aggressive brawn [16] (Midshipman A, 2015).

- "Various methods of "othering" that serve to strengthen the fraternal bonds of a predominantly male unit" such as body language and verbal language in jokes and metaphors or even directly. [3, p.5]

As a result of these activities, the manly warrior ideal is seen as and constructed in opposition to femininity and homosexuality. [18, p. 150]

All midshipmen are expected to conform to certain male standards, as delineated by years of naval tradition. Women are given special dispensation for fitness requirements on account of their "non-male" physiology. At times, this has put women at a disadvantage as they are perceived as less capable. One midshipman interviewed noted that "members of the male majority fail to recognize their own genetically privileged position for fitness performance and resent special allowances given to women "[Midshipman A]. This resentment serves to reinforce traditional perceptions that women cannot possibly be warriors. By being expected to meet only lower standards, women are not perceived as equals, even if they would be capable of meeting male standards. Moreover, the reliance on physical standards for officer qualifications with an absence of others, does not allow women to be recognized for other strengths they may possess.

While many gay men may meet the physical standards, their fear of being perceived as nonconforming to the masculine ideal can lead to emotional insecurity. In response, joking becomes one coping mechanism, a humorous attempt at "othering." Not surprisingly, Lesbian midshipmen have expressed less trouble openly identifying with the masculine stereotype than many gay men interviewed who do not feel as supported, especially when they would prefer to express themselves more flamboyantly. On coming out as a Lesbian, one midshipman writes:

"After coming out, I felt liberated from the concern about coming off as flirtatious to the guys. The sexual component in relationships with straight guys was gone. Being removed from that was nice." (Midshipman AH, 2015)
Women fit the warrior stereotype when they come out whereas many gay men have expressed that they do not.

\section{LGBT at USNA after DADT}

At first glance it appears that not much changed after DADT. According to some accounts, it seemed that a number of people who were gay came out that day, but still many remained "in the closet." The class of 2011 became known as the class that pioneered coming out at USNA but it was the class of 2013 that became known among midshipmen at the time as having a large number of "out" midshipmen. The class of 2013 was also the first class in which an openly gay couple attended the Ring Dance. Ring Dance is a traditional dance during which midshipmen celebrate the end of their second class (junior) year by dipping the ring in the water from the seven seas. Navarro (2015) remembers it as "a milestone event for publicity, the military, and the greater LGBT community." (Midshipman N., 2015). In May 2014, USNA hosted its first same-sex marriage. The only institutional response was that midshipmen regulations had a change: Instead of requiring midshipmen to keep the door to their rooms open when alone with the opposite sex, now it is required with anyone in the room.

Coming out is complicated and, while made easier under the repeal of DADT, it is not easy. In terms of the honor code, there is no longer a need to lie or get out. However, the process of self-discovery is impeded by the masculine warrior ideal that continues to thrive. On the upside, open jokes in my classrooms have, according to many faculty members teaching at USNA, all but disappeared. However, female bashing continues, less so in classes, but through traditions that continue (noted by midshipman A. - not allowing a female to make it to the top of Herndon, offensive terms to describe female midshipmen (Dumb Ugly Bitch or DUB TUB) and the like) and on social media such as Yik Yak.

According to initial participant-observation findings, men in the support organization SPECTRUM are rare than women. As the one of the participants in SPECTRUM offered, men frequently come once and then disappear, for fear they may be discovered by their friends or sports team members (as was one lacrosse player) or worse, "outed" when they themselves are not ready and fearful.

Those interviewed who are out, do not regret coming out and have not experienced marginalization, but the fear remains and perhaps rightly so: Those formerly openly opposed to Gays in the military are still peers and in leadership positions, only no longer openly expressing their homophobia. They are now underground and the repercussions of their strong opinions against the LGBT community are a concern for many.

Descriptions of the LGBT community at USNA vary, although many see it as a subculture, one that shares values and fosters a sense of common identity and community. 
One student explains: "The LGBT community at USNA is a small, tight-knit group that very strongly defines itself as a subculture. It is unique in the rest of the larger brigade in terms of sexual orientation, although there are straight members that identify with the community too. It is also unique in the context of society's larger LGBT community in that the members are part of the military... It is a support system, a conduit for dating, a safe haven, and a network" (Midshipman N, 2015). However, the diversity within the community can lead to a sense of alienation as well, as expressed by some who define themselves as Transgender.

\section{Trans at USNA}

Transgender midshipmen, like other LGBT people, believe that their gender identity is not a choice, but an inherent piece of who they are. They have known since very young that they do not fit the standard mold or that something was different about them. However, no matter how natural it is to be LGBT, society and especially the institution of the military, foster values and expectations that create hurdles for transgender people. From spaces defined by gender, such as bathrooms and bedrooms, to the language signifying gender and life events such as transitioning and coming out, these are all intensely personal, complicated parts of transgender life, not to mention life in a community which values uniformity. The following paragraphs subdivided by themes chosen to be discussed by midshipmen are based on their own words in interviews.

\section{On Coming Out as Trans at USNA}

Frequently, the stress levels of a transgender midshipman are directly correlated with how closeted they are. It is perhaps more common for a transgender midshipman that others in the LGBT community to live a double life of sorts because of both a fear of social isolation and the military policy. They often identify as the gender assigned at birth while in uniform, but express themselves according to their true identity while on liberty, dressing and socializing as such. This comes back to the internal conflict of living in an environment that stresses honor while not being able to legally come out. "It was ironic because by my firstie (senior) year, I was my company's honor adviser. Here I am telling everyone to live honorably, all while living my own lie.” (Midshipman M, 2016)

\section{On DoD Policy}

In summer of 2016, transgender service was finally approved by the Department of Defense after a panel research for a period of six months in order to determine specific rules and regulations regarding transgender people serving in the military. The panel was supposed to conclude in February of 2016 but was postponed. Transgender service members delayed their reporting dates and, as one explained in an article interview: "This is my dream career.... And I am sitting here atrophying" [2].

A similar panel was conducted regarding Don't Ask Don't Tell. For the DADT panel, researchers began with the supposition that, unless it can be proven that homosexuals in the military would not disrupt the mission, DADT would remain in effect. For the transgender panel, however, the underlying assumption is that unless it can be proven that transgender service threatens the mission, the regulation that prohibits transgender people servicing will be repealed. DADT was a law, passed by Congress. The ban on transgender service, however, is a military regulation which makes it easier to repeal.

When asked how the Navy could better facilitate life in the military for this community, one transgender USNA graduate felt strongly that the Navy should have come out with an interim guidance. The official policy required time, yes, but instruction on what those service members should do in the meantime would have been invaluable. Unlike Navy, Air Force did release an interim guidance.

\section{On Trans Acceptance at USNA}

While official guidance and instruction is crucial to the future of the transgender community in the military, it is military culture that most deeply impacts daily life. The culture of the Naval Academy, according to midshipmen themselves, is conservative. As a result, progressive social movements or lifestyles take time to become socially accepted.

The stigma of being transgender became apparent at the Academy when Caitlyn Jenner came out. It was a frequent topic of conversation, with midshipman asking "what is she?" or making jokes on the subject, deeming transgender people "its." For some transgender midshipmen who had not come out, this was a huge roadblock on the path to coming out.

Generally however, midshipmen do not volunteer negative comments about LGBT people unless the topic is brought up. Even then, comments are usually delivered in a joking manner. On the subject of other mids' opinions on being transgender: "Unless you have an open mind and you know people and you know something about being transgender, you wouldn't know how someone would think that way." (Midshipman S, 2016) Midshipmen interviewed understand that unless you walk in a person's shoes, you cannot know what it is like.

As mentioned above, USNA has a hyper masculine culture and is suspicious of any midshipman or officer who behaves "less than manly." (Midshipman N 2016) Consequently, transitioning from female to male is generally more acceptable than transitioning from male to female. "I'm giving up being up a man, and a lot of people 
don't get why I would do that," says midshipmen M, a transgender female Academy grad who comments on her noticeable loss of male privilege. Conversely, one transgender male midshipman says he "doesn't feel like [he] faces a lot of discrimination because [he's] one of us." (Midshipman S, 2016) When he came out to his female roommate, she was accepting or, in the words of this particular transgender midshipman, she "was fine with it."

Frequently though, even those who are supportive have qualms with certain aspects of transgender life being integrated into USNA culture. MIDN $S$ recalls a conversation during the school-wide ALLIES week, he and his roommate revealed that she does not support altering one's body in any shape or form. "She made it seem trivial - like an option that you don't have to use" (Midshipman S, 2016).

For MIDN S, the most stressful situations arise in his social life outside of the Academy. Going out, he tends to dress in a masculine fashion, but since he has not taken any physical steps to transition, he feels like he cannot pass as either gender and thus cannot rightly use either gender's bathrooms in public. The bathroom issue is a constant source of consternation for all transgender midshipmen. Gender neutral bathrooms are still rare in Annapolis and nearly absent on the Naval Academy campus.

There are people at the Academy who are accepting and even intrigued by the gender identity of transgender people. However, there is a risk of becoming a fetish, an object of habitual erotic response or fixation. Something so different from its surrounding - as being transgender is in the context of the Naval Academy - frequently runs such a risk. "[My girlfriend] doesn't really filter what she says. She told me she is more attracted to me because of the trans thing, which worries me." (Midshipman S, 2016)

At times, it is not just the Academy that presents the challenge, but the fleet, the prospect of life as an officer. MIDN S is especially worried about coming out in the fleet after graduation. "Here, people know me before I tell them about my identity - if I do - so they just adjust to a new me. But in the fleet, showing up and going through this, I feel like I'll be judged right off the bat. I don't really know what I'm getting myself into. (Midshipman S, 2016)"

The rigid construct of gender both at USNA and in the fleet is a source of concern that weighs on transgender midshipmen, diminishing their sense of self-esteem. Gender is important, visible, and defining for anyone. But at USNA it is problematized by the very fact that it is a highly gendered community to begin with: "It's difficult here because everything is so segregated by gender. The rooming situation, the bathrooms like anywhere else. But beyond that, like in our martial arts classes, boxing, different standards...it makes it harder..." (Midshipman K, 2016)" From the dress code to sports, every move a midshipman makes comes with expectations defined by gender stereotypes.

\section{Availability of Resources for the Trans Community}

According to midshipmen, when it comes to resources to facilitate transgender life, the Academy campus is lacking. There is one woman in the Leadership Ethics and Law Department (LEAD) on campus to whom many transgender midshipman have been referred for consultation sessions. There is also a bi-annual Safe Spaces workshop brought in by American University to educate both community members and allies alike. However, the Midshipman Development Center (MDC) does not mention offering trans-specific help and the chaplains have not touched the subject: "the MDC saying "hey, we help with LGBT issues too' or the chaplains going out of their way to say they are willing to help about those specific things would go a long way. I wish they were more visible" (Midshipman K, 2016). Spectrum has discussed trans topics, though infrequently, and is working to incorporate this specific sub community.

Many transgender midshipmen seek their community outside of Academy walls. There is a DC area gaming group for transgender military members and a Facebook group called Trans Officer Development. Sparta is another transgender group, but midshipmen may only join after they sign their 2-for-7 contracts. These groups are still being developed. While many transgender midshipmen speak out openly about the lack of resources, some have expressed a desire to be left alone and want to distance themselves from the group: "I should be reaching out in some ways. I could reach out and ask a lot of questions, but I think I want to struggle a little in a weird way. People are always willing to offer advice. But in some ways, I just want to go it alone." (Midshipman S, 2016)

\section{Transgender Language and Identity: the Pronoun}

Midshipmen are known to have their own language, one that includes acronyms and words most outsiders would not understand. This vocabulary is often a source of pride or a sigh of belonging. For the Transgender midshipmen, as for transgender civilians, pronouns, referring to a transgender person as "they" for example are an important but challenging aspect of life. "It's something a lot of people don't think about. I had a conversation with another plebe about pronouns...The plebe said, 'but that puts $m e$ at an inconvenience. I don't want to call her that.' But think about it. You get that basic respect every day without even having to try" (Midshipman K, 2016). It is common for transgender people to struggle with others adjusting to new pronouns, and because it is technically not legal yet for a midshipman to attend the Academy if transgender, convincing other midshipmen/officers to use the preferred pronouns is especially difficult. "My new roommate this semester has made the most effort with pronouns, at least correcting 
herself when she slips us. But the other one doesn't make an effort at all. And I don't know how to go about it - do I talk her? Do I correct her? I feel like she just doesn't try" (Midshipman K, 2016)

Still, there are exceptions. One plebe came out to their training staff (upperclassmen who are responsible for the professional development of freshmen at the Academy), who researched the subject and came back inquiring about appropriate pronouns, reflecting "I thought that was great, ya' know? I prefer people ask me questions instead of just assuming things" (Midshipman K, 2016)

Others who are not as "out" yet, deal with the conflict internally. A transgender male midshipman has not asked others at the Academy to use male pronouns in reference to him, because he does not want to make other people feel awkward. "I don't feel like being called that is necessary yet." (Midshipman S, 2016)

\section{Transition}

Surgery is a very personal, complicated decision for transgender midshipmen. Many are awaiting the policy release before taking official steps to transition. While personal feelings about one's identity are the foremost concern, medical procedures with its expenses, social stigma and military policy also contribute to the decision. When discussing their decision to transition, Midshipman K offers, "I do plan on getting top surgery, but as far as bottom surgery, probably not. Bottom surgery is not required for Olympic athletes to compete in a different sex than assigned at birth, so I expect military policy to follow suit." [20]

The transgender experience at the Naval Academy is diverse and complicated. Approach, responses, and feelings are varied from midshipman to midshipman. Midshipman S sums up his experience by commenting, "It's hard to explain to someone how I feel...There are certain things about being a male that I don't want to be a part of. I've experienced life as a female for 22 years, and I will carry some of those experiences over with me when I transition."

\section{Support of LGBT at Civilian Colleges: A Summary}

At many civilian colleges and universities, LGBTQA faculty members and students (note the addition of Queer and Asexual, terms not recognized by DoD) fear for their physical safety and worry about stigmatization and marginalization. While LGBTQA has become an acronym to cover the range of possibilities which are often hard to categorize, students and faculty members that are neither " $\mathrm{L}$ " nor "G" nor "B" nor "T" nor "Q" nor "A" feel their individuality remains stigmatized as a-typical and not recognized. It is for this reason that many colleges are trying to meet the needs of a more diverse student population than can possibly be defined by one acronym.
Many campuses have centers that offer mentorship, special locations to socialize and various programs. The University of Maryland at College Park, for example, has developed a network (the Rainbow Terrapin Network) which offers training for allies and specific training called Trans Advocacy, bringing the discussion to an intellectual level regarding gender theory and gender variance.

The University of Maryland furthermore operates a Speakers Bureau to ensure coverage in presentations and discussions in classes, dormitories and the like. As the website points out: " Members of the lesbian, gay, bisexual, transgender and allied community who have received training for this purpose enter into these discussions and prepare to disseminate accurate information, to answer questions that students, staff and faculty may have about the realities of LGBTQA lives, and to introduce the heterosexual, gender normative majority to visible members and allies of this mostly invisible minority" [21] (http://www.umd.edu/lgbt/guide.html). In order to recognize such members and allies, awards have been drafted to recognize "Champions of Our Community," "Defender of Diversity," "Pride Awards," and "Advocate for Equity".

Beyond these larger programs, there are a number of support centers including the Office of Diversity and Inclusion, Assistance for LGBTQA students, the Counseling Center which offers "Rainbow Walk-In Hours," a focus in the Study Abroad Center to help LGBTQ students with study abroad concerns, LGBTQA Health and Sexuality Resources and finally, the One Project:

"The One Project is the First-Year Experience (FYE) program for Lesbian, Gay, Bisexual, Transgender, Queer and Ally students at the University of Maryland" ensures that LGBTQA-identifying first year students make a successful transition to college. The One Project focuses on LGBTQA students and helps students reach their full potential, just as any other student at the university might. It also works to integrate LGBTQA includes more gender diversity than, for example, the military academies, and hopes to build a community that, according to their own description: "can come together in an intellectual, social and civically-minded way to support each other through the first year of college" (http://www.umd.edu/lgbt). It is with this support that LGBTQA students can feel empowered and equally at home on college campuses. The University of Maryland is one of many colleges and universities that offer a wide range of opportunities to promote the success of LGBTQA students. If indeed the military academies hope to represent civilian society they can look beyond their walls.

\section{The Value of an Ally}

Invaluable to any program is an ally, that is, someone who advocates for and supports members of a community other than their own. An ally is someone who is committed 
to understanding patterns of marginalization and is willing to challenge such behavior of others. In our context today, an ally is a straight person or heterosexual individual who fights for civil rights of LGBT people [6]. Their identity as allies means that they have gone through a conscious process of personal development to identify as allies.

An ally to LGBT individuals is a person who:

- develops an understanding of gay, lesbian, bisexual, and transgender issues. Works to be comfortable with her/his knowledge of gender identity and sexual orientation.

- attends workshops and discussions, continues to be open developing LGBT issues.

- understands how patterns of oppression operate, is willing to identify oppressive acts and challenge the oppressive behaviors of others. An ally, especially an academic, will study LGBT issues, historical tendencies and political and social patterns.

- finds a way to feel personally capable of confronting/combatting homophobia and heterosexism. An ally is willing to speak up and speak out.

- Similar to how an LGBT person "comes out of the closet," an ally "comes out" as an ally by publicly acknowledging her/his support for LGBT people and issues. While the event of coming out as an ally may not appear to be so significant, it depends on the person's social and cultural context and experiences. The act of coming out publicly in and of itself will strike a chord with surrounding people and can engender thought and discussion. Being an ally can be contagious.

Whether or not they disclose their sexual orientation, allies face similar issues simply by coming out as an ally. One student, upon giving a presentation on her experience with the LGBT community in the military writes:

"I felt like I made a hard statement on my position that has the potential to lump me into the "hated group." There were plenty of people in the audience who seemed interested in my project and absorbed what I had to say. But then, I did notice a couple of mids whispering to each other, nervously laughing, or making faces while I was speaking. Whether these things were done out of opposition or hate, it is hard to say. Regardless, I was nervous getting up there to present despite how strongly I feel about supporting the LGBT community. It was a microcosm of the trepidation I can imagine the community itself feels, so it was a valuable experience both personally and as an extension of my study" (Midshipman N., 2015).

- An Ally is aware that she/he may be called the same names and be harassed in similar ways to those whom she/he is defending.

- Chooses to align with LGBT individuals, and represents their needs - especially when they are unable to do so themselves. If and when and
LGBT person cannot speak for herself for whatever reason, an ally can step in.

- Promotes a sense of community with LGBT individuals, and teaches others about the importance of these communities. Encourages others to also provide advocacy. [](see Fingerhut 2011)

Allies have a powerful role to play in changing attitudes. People who are prejudiced can have their attitudes changed simply by knowing that people they know have friendships with LGBT people. Allies of the LGBT community range in their engagement, from those "who challenge assumptions and jokes about gay people to those who volunteer time and money to organizations that advocate on behalf of LGBT issues... These allies have worked to change one mind at a time, often voicing their opinions despite potential stigmatization" [6].

One example:

"At the West Point Military Academy, former student Alexander Raggio used his senior honors thesis to advocate for LGBT rights. In his thesis, Raggio critiqued the Pentagon's "don't ask don't tell," policy... Raggio, who describes himself as "about the straightest guy you can imagine" (West Point Senior Thesis 2006), won the award for best senior thesis at the Academy's English department" [6].

According to some midshipmen, the reality is that LGBT is not completely accepted. "L is better than G. B? no one sells themselves that way. T-well, perhaps we are getting there." (Midshipmen A, 2015).

Overall there is a sense by midshipmen and officers that DADT has not entirely disappeared. Many people feel uncomfortable living and working with LGBT members and do not want to be reminded of them. As one student states: "I am all too aware that there are people at the Academy who are openly against the LGBT community and, in much larger numbers, there are people who are avidly against the community but are socially conditioned enough not to make overtly hateful comments" (Midshipman N., 2015).

It is this latter statement that needs to be studied and understood in order to begin to pave the way for creating a support system that can lead to the success of LGBT midshipmen.

\section{Conclusions}

Culture may be defined as the shared patterns of behaviors and interactions, cognitive constructs, and affective understanding that are learned through a process of socialization (CARLA.umn.edu accessed May 2016) which occurs both consciously and subconsciously through human interaction. These shared patterns identify the members of a culture group while also distinguishing itself from those of another group. The LGBT community is growing a culture, especially as it identifies itself with 
subcultures of its own depending on variations in gender groups. Its official acceptance in the U.S. military and its academies has proven extremely important not only to those members within the military community, but also as legitimizing in the United States. As an institution, the military tries to stay at the forefront of social changes, reflecting the reality of Northern American society, in effect helping to legitimize the LGBT community as an accepted group. As such, the U.S. military is working to accept and reflect ethnic and gender diversity. It is through the actions a praxis of the LGBT community that this change will come about but only if the Academy is open to listening and learning.

The Naval Academy reaches out to ethnic minority and female students, encouraging those with military and academic promise to apply. LGBT students have not reached such a level of acceptance by recruitment but with changes in official regulations, LGBT midshipmen are looking to be fully integrated as officers. Today's midshipmen are experiencing a culture of change, one that was unfathomable at the turn of the $21^{\text {st }}$ century. To ensure that the change flourishes without hurting minority students, it is imperative that the academies build an infrastructure that supports a climate of change and not only reflects the reality of Northern America's social stratification but also changes that are occurring at civilian colleges in terms of support structures. Using academic institutions of higher learning as models for support of life-long learners and contributors to society, a more thoughtful approach to fostering academic and personal growth would greatly improve the prospects for our future officers.

\section{Appendix}

\section{Consent Agreement Blank:}

\section{UNITED STATES NAVAL ACADEMY}

589 MCNAIR ROAD

ANNAPOLIS MD 21412

\section{Informed Consent Form for}

Name of Principle Investigator: Dr. Clementine

Fujimura

Email of Principle Investigator: cfujimur@usna.edu

Name of Organization: U.S. Naval Academy

Name of Project and Version: "LGBT at USNA"

This Informed Consent Form has two parts:

- Information Sheet (to share information about the study with you)

- Certificate of Consent (for signatures if you choose to participate)

You will be given a copy of the full Informed Consent Form

\section{Part I: Information Sheet}

Introduction

I am working as an independent researcher and am conducting research on the experience of being a gay midshipman. You have been invited to be a part of this study. You do not have to decide today whether or not you will participate in the research. Your decision to participate is completely voluntary and you may elect to discontinue participation in this study at any time. The research will be conducted until 1/13/14.

Purpose of the research

The purpose of this project is to study the gay community at USNA using qualitative ethnographic research to identify cultural needs within the academy. The study is an outcome of recent data collected by the Palm Center suggesting that stereotypes of gays in the military are still leading to marginalization (Belkin 2012) and that a need exists to acknowledge continuing and new concerns in the aftermath of DADT. This study seeks to uncover in the words of the midshipmen themselves (albeit anonymously) their experiences at USNA, their struggles and dreams as future Navy and Marine Corps officers. Via a collection and analysis of their own narratives presented both orally and in writing, we hope to discover the reality of what it means to be a gay male midshipman at the academy in the beginning of the $21^{\text {st }}$ century. How has life for gays changed since DADT if at all? Do students have a sense of community and to what extent are individuals part of a subculture? How does the community define itself and what are their visions for the future? How can the institutional culture support gay midshipmen and possibly accommodate this new subculture, if it exists?

Type of Research Intervention

This research will involve your participation in in-person or via email and you will be asked to provide a narrative in writing.

\section{Participant Selection}

If you are a gay midshipman and are willing to provide a narrative description of your experience as such, along with some responses to the investigator's follow-up questions about your narrative, I hope you will consider participating in this study.

\section{Voluntary Participation}

Your participation in this research is entirely voluntary. It is your choice whether to participate or not.

The choice that you make will have no bearing on your job or on any work-related evaluations or reports. You may change your mind later and stop participating at any time during the interview processes.

Risk

There is no physical risk. However, should you experience any distress, you are asked to contact the 
researcher immediately to discuss this and explore referral options for support and assistance.

\section{Confidentiality}

I will not share identifiable information about you with anyone. To help protect your privacy, I ask that you use aliases for both yourself and others you may mention in your written or verbal responses. The information that I collect from this research project will be kept private. I may further alter specific demographic information in order to further protect your privacy. Only the researcher will know what your alias is and I will lock that information securely in my office. An article and a book may be written on the subject, but again, you will not be identified as a participant in this study.

This proposal has been reviewed and approved by the U.S. Naval Academy IRB, which is a committee whose task is to make sure that research participants are protected from harm. If you wish to find about more about the IRB, contact the IRB office at USNA.

\section{Part II: Certificate of Consent}

I have read the foregoing information, or it has been read to me. I have had the opportunity to ask questions about it and any questions I have been asked have been answered to my satisfaction. I consent voluntarily to be a participant in this study

\section{Print Name of Participant}

Signature of Participant

Date

Day/month/year

Name of Researcher/person taking the consent

\section{Signature of Researcher/person taking the} consent

Date

\section{REFERENCES}

[1] Barrett, Frank, J., "The Organizational Construction of Hegemonic Masculinity: the Case of the U.S. Navy," in Gender, Work, and Organization, July, 1996, vol. 3 (3). pp. 129-141.

[2] Jedra, Christina, "Unchartered Territory: Career of Transgender Naval Academy Graduate Stalled by Defense Policy" in The Capital Gazette, June 26, 2016. Pp. A1, A7.

[3] Brest van Kempen, Gillian, "Feminist Analysis of the Customs and rituals at USNA" unpublished paper, 2003.

[4] Burks, D.J. "Lesbian, Gay and Bisexual Victimization in the Military: An Unintended Consequence of 'Don't Ask Don't Tell'?' in American Psychologist, vol 66(7), October 2011, pp. 604-613.

[5] Cameron, Rebecca P. et al, "Sexuality Among Wounded Veterans of Operation Enduring Freedom, Operation Iraqi
Freedom, and Operation New Dawn: Implications for Rehabilitation Psychologists" in Rehabilitation Psychology vol 56(4), November 2011, pp. 289-301.

[6] Fingerhut, Adam W. (2011) "Straight Allies: what Predicts Heterosexuals' Alliance with the LGBT Community?" in Journal of Applied Social Psychology, 41, 9, pp. 2230-2243.

[7] Frank, Nathaniel et. al. "What Does the Empirical Research Say About the Impact of Openly Gay Service on the Military?' A Research Memo for the Palm Center, March 3, 2010. www.palmcenter.org accessed May 2015.

[8] Herek, Gregory M, Jobe, Jared B. and Carney, Ralph M. (1996) Out in Force: Sexual Orientation and the Military, Chicago: The University of Chicago Press.

[9] Johnson, W. Brad et al. “After Don't Ask Don't Tell: Competent Care of Lesbian, Gay and Bisexual Military Personnel During the DoD Policy Transition" in Professional Psychology: Research and Practice, Vol 46(2), April 2015, pp. 107-115.

[10] Levine, Joe (1996) "The Long Way Home" The University of Chicago Magazine, http://magazine.uchicago.edu/9602/9602 Ortner.html accessed May 22, 2016

[11] Lyman, Peter, (2001) "The Fraternal Bond as a Joking Relationship: A Case Study of the Role of Sexist Jokes in Male Group Bonding" in Men's Lives, Needham Heights, Massachusetts: Allen \& Bacon.

[12] Michaels, Ben, "Gender Studies and Anthropology" http://www.indiana.edu/ wanthro/disciplines-and-subdiscipl ines/national-traditions/gender-studies

[13] Nanda, Serena (2000) Gender Diversity: Cross-cultural Variations, Illinois: Waveland Press

[14] Ortner, Sherry (1974.) Is female to male as nature is to culture? In M. Z. Rosaldo and L. Lamphere (eds), Woman, culture, and society. Stanford, CA: Stanford University Press, pp. 68-87.

[15] Ortner, Sherry (2006) Anthropology and Social Theory: Culture, Power, and the Acting Subject, Durham, NC: Duke University Press.

[16] Ramirez, Maria H. "If We Ask, What They Might Tell: Clinical Assessment Lessons from LGBT Military Personnel Post-DADT" in Journal of Homosexuality, vol 60(2-3), 2013, pp. 401-418

[17] Ranken, Susan R. (2003) Campus Climate for Gay, Lesbian, Bisexual and Transgender People: A National Perspective, The Policy Institute of the Gay and Lesbian Task Force. http://www.bestcolleges.com/features/best-colleges-for-lgbtstudents/Accessed April 11, 2016.

[18] Snyder, R. Claire "Troubling Armed Maculinity: Military Academies, Hazing rituals, and the Reconstitution of the Citizen-Soldier" in Citizen-Soldier and manly Warriors: Military Service and Gender in the Civic Republican Tradition, New York: Rowman and Littlefield, 1999.

Interviews quoted:

Midshipman TS, December 2010

Midshipman A, March 2015

Midshipman AH, April 2015

Midshipman K, - February 2016

Ensign Alexandra M, - May 2016

Midshipman N, April 2015 and numerous conversations in 2016

Midshipman S, - May 2016 